\title{
A HISTÓRIA REGIONAL E O USO DE TECNOLOGIAS DIGITAIS DA INFORMAÇÃO E COMUNICAÇÃO (TDIC'S) EM SALA DE AULA
}

\author{
REGIONAL HISTORY AND THE USE OF INFORMATION AND COMUNICATION \\ TECHNOLOGIES (ICTS) IN THE CLASSROOM
}

\author{
Taís Temporim de Almeida ${ }^{1}$ \\ Lourdes Madalena Gazarini Conde Feitosa² \\ Fábio Paride Pallotta ${ }^{3}$ \\ Laís Prestes Redondo 4 \\ Gabriela Isbaes 5 \\ Marco Antonio de Morais Jr. ${ }^{6}$
}

\begin{abstract}
RESUMO: Em tempos de globalização torna-se cada vez mais necessário conhecer o local em que se vive, para nele ser possível atuar de forma consciente e cidadã. Frente a este desafio do conhecimento do mais próximo, do que nos diz respeito, de onde vivemos e devemos agir em primeiro lugar, bem como da construção e aplicação deste conhecimento como instrumento de ensino e aprendizagem escolar é que se apresenta, nesse artigo, as reflexões e resultados obtidos e compilados durante o ano de 2017, em atividades do projeto de História - "Bairros, patrimônio e memória: a história da cidade de Bauru a partir de seus espaços urbanos", financiado pelo Programa Institucional de Bolsa de Iniciação à Docência (PIBID/CAPES). As atividades foram desenvolvidas por um grupo de graduandos e professores do curso de História da Universidade do Sagrado Coração de Bauru - SP, com alunos do $6^{\circ}$ ano da escola Estadual Edison Gasparini, localizada no Bairro de nome homônimo. Dois desafios foram cruciais para o desenvolvimento desta proposta e nos motivaram a refletir a respeito do tema: primeiro, como o uso de ferramentas das Tecnologias da Informação e Comunicação (TDIC's) poderia contribuir para a construção de conhecimentos relacionados à história do local com alunos dos anos finais do ensino fundamental (EF), e, segundo, como envolvê-los na formulação deste saber. Desse modo, os resultados compartilhados nesse texto têm por objetivos apresentar as possibilidades de produção de conteúdo em história local com o uso destas tecnologias e a sua articulação com o ensino. Além disso, de contribuir para a disseminação e popularização de informações a respeito destas práticas, que poderão nortear futuras situações escolares no processo de ensino-aprendizagem em História.
\end{abstract}

Palavras-chave: História. História local e regional. Ensino. Aprendizagem. TDIC'S.

1 Mestranda do Programa de Pós-graduação em Educação da Faculdade de Educação da Universidade Estadual de Campinas/SP. E-mail: temporimtais@gmail.com.

2 Doutora em História Cultural pela Universidade Estadual de Campinas/SP. Professora do curso de História e Coordenadora do Stricto Sensu em História, ambos do Centro Universitário Sagrado Coração, Bauru/SP, e professora do Programa de Mestrado em Educação Sexual da Unesp/Araraquara/SP. E-mail: loufeitosa@uol.com.br.

3 Mestre em História e Sociedade pela Unesp/Assis/SP. Professor do Centro de Ciências Humanas do Centro Universitário Sagrado Coração, Bauru. E-mail: fabioparide@gmail.com.

4 Graduada em História e especializanda em História, Cultura e Poder, ambos pelo Centro Universitário Sagrado Coração, Bauru/SP. E-mail: laisprestesredondo@gmail.com.

5 Mestranda do Programa de Pós-graduação em História do Instituto de Filosofia e Ciências Humanas da Universidade Estadual de Campinas/SP. E-mail: gabyisbaes@gmail.com.

${ }^{6}$ Graduado em História pelo Centro de Ciências Humanas do Centro Universitário Sagrado Coração, Bauru/SP. E-mail: mamjunior@outlook.com. 
ABSTRACT: In times of globalization it becomes important to know the place where the person lives, in order to be able to act in a conscious and citizen way. Faced to the challenge of to know what happens in the neighborhoods, of that concerns us from where we live and we must first act, as well as the construction and application of this knowledge while an instrument of teaching and learning is presented, in this article, reflections and results from compiled reports relative to the year 2017, in activities linked with the Project "Neighborhoods, heritage and memory: the history of the city of Bauru from its urban spaces", that was sponsored by the Institutional Program of Initiation to Teaching (PIBID/CAPES). The activities were developed by a group of undergraduates and professors of the Course of History, University of the Sacred Coeur of Bauru - SP, with 6th grade students of Edison Gasparini State School, located in the district with the same name. Two challenges were crucial for the development of this proposal and they have motivated us to reflect on the subjects: first, how the use of Technologies of Information and Communication (TDIC's) could contribute for the construction of knowledge related to the place history with elementary students and, second, how to involve them in the formulation this knowledge. Thus, the results shared in this text have as aim to present possibilities of production of local history contents using technologies and to establish articulation with teaching. Besides that, it is hoped for some contribution in the dissemination and popularization of these practices, which may guide future school situations in the process of teaching-learning local History.

KEYWORDS: History. Local and regional history. Teaching. Learning. ICTs.

\section{Introdução}

O repensar do conhecimento e do ensino de História faz parte de uma trajetória crítica pela qual passou a disciplina ao longo do século $X X$, de modo mais acentuado em suas últimas décadas. Ecos destes debates, originados em lugares diferentes e com enunciados variados, como, por exemplo, pela Escola dos Annales, Teoria Crítica Marxista, Epistemologias Feministas, Psicanálise, Corrente do Desconstrutivismo e pelo Pós-Modernismo, foram direcionados aos paradigmas tradicionais das Ciências Humanas. Tais análises chamaram a atenção para o uso do método científico alicerçado em análises macroestruturais e em ideias universais dadas pelo "resgate" de contextos históricos; pela existência de sujeitos universais como "povo", "homem", "populares", além da crença na objetividade do discurso científico e na onisciência do narrador, projetando uma imagem de autoridade à análise como se fosse a própria recuperação do passado (FEITOSA, 2005; RAGO; GIMENES, 2014).

Essas discussões conduziram a novas abordagens sobre o conhecimento científico e influenciaram, no campo histórico, no deslocamento da meta- 
narrativa, dedicada aos "grandes" personagens, para narrativas interessadas no heterogêneo, no local e no específico, focadas em temas até então não pesquisados, como a história dos trabalhadores, dos marginais, dos negros, das mulheres, das crianças, dos indígenas, da sexualidade, do corpo e dos grupos populares, dentre outros. Ampliaram-se os domínios historiográficos, o conceito de documento e as tarefas do historiador (MATTOSO, 1988; SAMUEL, 1990). O objeto central da História mudou-se do tempo para o homem (BLOCH, 2001, p. 54), e para a relação entre este e o espaço. Isto é:

[...] as ações e transformações que afetam aquela vida humana que pode ser historicamente considerada dão-se em um espaço que muitas vezes é um espaço geográfico ou político, e que, sobretudo, sempre e necessariamente constituir-se-á em espaço social (BARROS, 2006, p. 465).

Conceitualmente, os termos regional ou local podem ser considerados como sinônimos ${ }^{7}$. O que define a História Regional ou Local, de início, é o seu recorte geográfico ou administrativo, mas que só adquire sentido quando analisado em conjunto com o "espaço social" e os elementos culturais que o integram, como enfatizado por Silva e Pereira (2016, p. 312-313):

Não nos parece suficiente o mero reconhecimento do "recorte espacial" da pesquisa histórica como definidor de região. Trata-se, sim, de perceber os processos sociais que produzem o espaço e como o conceito de "região", ao incorporar na análise a perspectiva relacional (uma região somente se define como região na sua relação com outras), revela os mecanismos de produção e reprodução de desigualdades espaciais. Essa abordagem, naturalmente, não se limita aos aspectos políticos ou econômicos, mas também às construções culturais, identitárias e simbólicas que nos constituem enquanto sociedade. A própria opção tecnológica pela internet significa um desafio à hierarquização, naturalizada na produção acadêmica, que cria regiões centrais e periféricas.

Portanto, a delimitação espacial não é muito precisa, mas as dimensões desta forma de produção podem abranger um município, um de seus bairros ou

\footnotetext{
7 História Regional e/ou Local é usado no mesmo sentido por Mattoso (1988), nas páginas 177, 178, 179 e180, e Martins (2009), nas páginas 134, 135 e 136. O mesmo significado também é visto quando mencionado apenas como História Local, como fazem Neves (1997); Nogueira e Silva (2010); ou como História Regional, por Caprini (2010) e Silva e Pereira (2016).
} 
uma característica cultural de determinados locais de uma cidade ou de uma região mais ampla. O importante é que, "para pensar e regionalizar o espaço construído por sociedades [...] é preciso levar a sério a historicidade das formações espaciais" (MARTINS, 2009, p. 145).

Esta história faz emergir microcosmos, eventos eminentemente particulares, embora conectados e compreensíveis quando articulados às esferas nacional e global. Isto porque a identificação da vida social local, em seus aspectos políticos, econômicos e culturais, expressa a dialética com o nacional e o global e com as suas tensões, sobreposições e justaposições de poderes (MATTOSO, 1988, p. 174). Ou seja, o espaço é um "campo de forças" no qual se opera variados discursos e memórias (BARROS, 2006, p. 475).

Outrossim, no que diz respeito ao ensino de História, muitas modificações ocorreram sob as mesmas aliterações passadas pela ciência histórica. Pensando cada vez mais na dinamização do ensino, na sua acessibilidade e nas possibilidades do currículo para alunos e professores, as quatro últimas décadas assinalaram essa mudança no trato da História, para além de reducionismos atrelados a uma suposta hierarquia de sua versão enquanto ciência ou enquanto disciplina (MARTINS, 2007). Nomes como Arlette Medeiros Gasparello, Maria Aparecida Leopoldino Tursi de Toledo, Circe Maria Fernandes Bittencourt, Jaime Pinksy, Maria do Carmo Martins, Maria Carolina Bovério Galzerani e Ernesta Zamboni são divisores de águas sobre o ensino de História no pós-1990, produzindo e problematizando a respeito da escola, sua inserção no meio e os diálogos que essa estabelece com o currículo, o ensino e a educação.

Nesse sentido, enquanto a microhistória propunha um olhar a partir da redução de escalas, o ensino passou a promover um olhar acerca do espaço social, suas especificidades, bem como as articulações e disputas presentes nesses, o que fundamentou a promoção da História Regional, cujo propósito é estimular o aluno a ser atuante na construção da dinâmica social e histórica do espaço onde vive.

Este conjunto de mudanças exigiu que o Ensino de História no Brasil também fosse (re) pensado e questionado, uma vez que as narrativas gerais sobre o nacional e a história de alguns grupos então destacados já não mais atendiam aos anseios de busca pela pluralidade e polifonia até então excluídas; 
As disputas em torno do ensino de história a partir dos anos 1980 revelou uma década de tensões e criatividade. Os vícios do autoritarismo vão de encontro às transformações que exigem uma mudança de mentalidade. Procura-se dar voz aos excluídos. Tentase romper radicalmente com a forma tradicional de se ensinar História, buscam-se novas fontes, novos materiais. As propostas expressaram sem dúvidas a necessidade de se trazer para discussão ações e sujeitos até então excluídos da História que se ensinava (PAIM; PICOLLI, 2007, p. 5).

Estas proposições a respeito da história local refletiram-se nas propostas curriculares nacionais, principalmente nos Parâmetros Curriculares Nacionais (PCN) para o EF e Ensino Médio (EM). O ensino da história local suscitou um período de debates e passou, com o PCN de História, a ser adotado por várias escolas como estratégia pedagógica, com a transposição do saber histórico para o saber escolar (SCHMIDT; CAINELLI, 2004).

Desde então, propostas curriculares, projetos político-pedagógicos e pesquisadores da área do ensino de História defendem e discutem inúmeras possibilidades de trabalhos e estratégias de ensino e aprendizagem sobre o local (BRASIL, 1998a). Esse debate resultou em algumas vantagens como produzir a inserção do aluno na comunidade da qual faz parte, recriando sua cidadania, historicidade e identidade (NEVES, 1997). Por meio de atitudes investigativas, favorece uma análise mais diversificada da realidade social, política, econômica e cultural e estimula a percepção sobre as mudanças e permanências, continuidades e rupturas, e viabiliza que vozes do passado silenciadas ou ofuscadas emerjam com suas versões, através das investigações feitas pelos estudantes. Como destaca Mattoso (1988, p. 180), "[...] o estudo do passado local ou regional pode ser extremamente gratificante para quem procura conhecer-se a si próprio e ao mundo a que pertence".

A relevância desta proposta está no fato de que a História Local, apesar de ser incluída nos Parâmetros Curriculares Nacionais (PCN) durante os anos iniciais do $E F$, não se estende de modo pertinente às séries subsequentes a esse - $6^{\circ}$ ao $9^{\circ}$ ano (BRASIL, 1998b). Compreende-se, assim, como o trabalho realizado em determinado momento não encontra continuidade e meios de se correlacionar com os conteúdos históricos trabalhados nos anos finais do EF que privilegia a história nacional e internacional, com rara conexão com a história regional. 
A possibilidade de trabalhar com este tema surgiu com o subprojeto em História "Bairros, patrimônio e memória: a história da cidade de Bauru a partir de seus espaços urbanos", realizado no ano de 2017, a partir do estímulo do Programa Institucional de Bolsa de Iniciação à Docência (PIBID), financiado pela Coordenação de Aperfeiçoamento de Pessoal de Nível Superior (CAPES). Dentre as prerrogativas do programa destaca-se a inserção dos licenciandos no cotidiano de escolas da rede pública de educação com a finalidade de lhe proporcionar oportunidades de criação e participação em experiências metodológicas, tecnológicas e práticas docentes de caráter inovador, de tal modo que possa articular teoria e prática ainda durante o período de sua formação ${ }^{6}$. subprojeto de História foi um dos braços de um projeto maior composto por dez áreas, dentre elas Biologia, Filosofia, História, Matemática, Pedagogia, Teatro/Artes cênicas, Letras-Inglês, Letras-Português, Música e Interdisciplinar, orientados por professores da Universidade do Sagrado Coração. As atividades foram realizadas na Escola Estadual Edison Bastos Gasparini, localizada em bairro homônimo, em Bauru. Procurou-se conciliar a temática da História Local com o uso das Tecnologias Digitais da Informação e Comunicação (TDIC's) no espaço intraclasse, para melhorar e aproximar a relação estabelecida entre alunos e conteúdos de História. Nesse aspecto, apresentamos, abaixo, uma breve análise de conceitos considerados importantes para esclarecimento sobre as TDIC's, as quais se enquadram no norte desse texto: refletir sobre como o uso de ferramentas das Tecnologias da Informação e Comunicação (TDIC's) poderia contribuir para a construção de conhecimentos relacionados à história do local com alunos do $6^{\circ}$ ano e meios de envolvê-los na formulação deste saber.

Assim, unimos discussões teórico-metodológicas ao trabalho de compilação documental, buscando a promoção de saberes e de informações acerca da História Local e Regional da cidade de Bauru, a partir do uso de mídias digitais e sites. De modo a destacar a produção de conhecimento a respeito do local pelos estudantes, nosso trabalho consistiu em uma intervenção pedagógica que pontua sobre a inserção e promoção da autonomia do aluno no processo de construção do conhecimento mediado por sua própria realidade, propiciando, nesse sentido,

6 Cf. em Brasil (2018) 
uma melhor compreensão da interrelação entre a história da localidade com a nacional e internacional.

\section{Tecnologias Digitais da Informação e Comunicação (TDIC's) no ambiente escolar}

É notório, nos dias atuais, como o uso de tecnologia digital já é, em grande parte, uma realidade no contexto mundial e como a sua aplicação abrange diferentes e variadas instâncias. A presença de uma cultura digital é irreversível também na educação, tornando-se cada vez mais requisitada e utilizada sob variados pretextos e objetivos, em uma relação que tende a um estreitamento de laços entre alunos, professores e, sobretudo, conteúdos. Observa-se como a educação é a principal vencedora da tríade formada por tecnologia, educação e conteúdos trabalhados, pois os alunos atendidos pela atual Educação Básica tendem a ter relações substancialmente mais próximas às informações, facilitadas pelo acesso à tecnologia. Eles também têm maiores habilidades para utilizá-las, o que favorece amplas possibilidades exploratórias e sua aplicação no processo de ensino, bem como em sua formação geral (KENSKI, 2003 apud COSTA; DUQUEVIZ; PEDROZA, 2015).

Esses estudantes são caracterizados pela terminologia dos Estudos Educacionais sobre Tecnologia como "nativos digitais", isto é, aqueles que nasceram após a década de 1990, cresceram cercados pelo advento da tecnologia e suas inovações, o que os faz ter rápido, constante e integrado acesso cotidiano às novas tecnologias (FRANCO, 2013; PRENSKY, 2001 apud COSTA; DUQEVIZ; PEDROZA, 2015). Um número significativo de alunos matriculados hoje no Sistema Educacional está conectado a essa realidade digital, o que Ihes permite aprender simultaneamente de diversas maneiras, a partir de situações múltiplas, não mais totalmente dependentes da Escola, de seus livros e professores. Embora seja perceptível o grande crescimento de alunos que têm à mão um mundo de redes interligadas pelo acesso digital por meio de seu smartphone, a maioria dos que se sentam hoje nos bancos escolares ainda recebe uma educação bancária e centralizada no professor (FREIRE, 1987). 
Esses discentes que pesquisam por si só, questionam e aprendem de maneira diversa, diferente de duas gerações anteriores, também são aqueles que apresentam dificuldades em ser completamente autônomos nessas atividades (ALVES, 2014). Reunir, selecionar e analisar informações são noções primordiais no mundo contemporâneo. Todavia, segundo Alves (2014), os nativos digitais, mesmo com toda habilidade já reconhecida no uso do computador e das demais mídias digitas, precisam desenvolver discernimento e capacidade crítica para selecionar as informações coletadas na internet. Por esse motivo, quando se observa que as TDIC's são cada vez mais frequentes e incorporadas em diversos meios, compreende-se a importância e o papel da Educação neste processo e a sua necessária abertura às novas possibilidades vivenciadas no mundo extraescolar. Levar a tecnologia ao seu interior e desmitificar usos e desusos sobre essa e sua aplicabilidade em sala de aula é fundamental para torná-la uma aliada no processo de ensino-aprendizagem. Urge, portanto, dentre nós, professores, deixarmos que o receio e a reticência quanto a seu uso sejam argumentos para excluir sua validade, fazendo com que alunos sejam desmotivados diariamente pelo sistema que os cerca, mesmo porque cabe ao professor 0 importante papel de organizar 0 conhecimento gestado coletivamente em sala (BIZELLI; GERALDI, 2016, p. 146). A premissa básica deve mudar e incentivar a incorporação de tecnologias que formem alunos a ser terra fértil às novas proposições e descobertas acessíveis por meio dela, e que serão aplicadas no ambiente escolar, bem como muito além dele.

Subentende-se, à vista disso, que ao fazer uso das TDIC's como suporte de situações pedagógicas, trabalha-se no sentido de mudar aspectos engessados da Educação de modo a conceber uma nova maneira de apropriação crítica das mesmas, com o propósito de tornar o aluno analítico e interlocutor ativo do conteúdo à sua frente. Torná-las uma importante ferramenta de uso pedagógico comungará com a realidade dos alunos, de modo a inovar metodologicamente, envolvendo tanto alunos e professores no sentido de produzir e aprender de modo diferente, o que se expressa em um desafio aos dois, mas que, bem articulado e trabalhado, tende a ótimos resultados.

Logo, evidenciam-se as amplas e multifacetadas possibilidades didáticas disponíveis hoje frente a um computador, smartphone, tablet, ou qualquer uma 
das inovações midiáticas disponíveis ao grande público. A sua aplicação possibilita a interação, inclusão digital e, principalmente, a construção de aspectos variados relacionados à aprendizagem, como o exercício e aprimoramento da criatividade, da atenção, da concentração e da percepção. Desta maneira, o uso apropriado de Tecnologias Digitais da Informação e Comunicação resulta em ganhos à sala, construindo e ligando conhecimentos e alunos.

\section{A importância da História Local e sua articulação com as TDIC's: a experiência com os $6^{\circ}$ anos da escola Edison Gasparini de Bauru-SP}

Pinsky e Pinsky (2007) apresentam a História enquanto disciplina que estuda o homem em suas relações sociais, culturais e políticas, o que a faz ser contribuinte da elaboração de um novo meio de se olhar o passado, questionando o presente e suas realidades a partir de vivências e experiências. Entretanto, a realidade que permeia muitas aulas de História é a de informações desconexas em livros didáticos e, por vezes, apresentadas de modo positivista e linear (ASSIS; BELLÉ; BOSCO, 2013; PINSKY; PINSKY, 2007), o que faz com que os estudantes sintam-se distantes, em diversos sentidos, do proposto em aula. Portanto, um novo pensar histórico corrobora-se pelo "buscar por meio de aulas dinâmicas envolver o aluno" (ASSIS; BELLÉ; BOSCO, 2013, p. 3).

Ante isso, o ensino de História Local articula-se como as novas abordagens propostas, ao mesmo tempo em que procura desenvolver a formação do senso crítico do aluno, uma vez que esse se vê no desenvolvimento da história e nas micro relações de poder nela expressas. O estudo da História Local acaba por se associar à ideia de transversalidade no conteúdo, o que possibilita à disciplina ser única e significativa aos discentes, justamente como proposto em textos dos PCN (FREITAS NETO, 2016). Os alunos buscam, partilham, vivem e pesquisam o ambiente em que moram, suas memórias seletivas, questionam o seu entorno e, principalmente, desenvolvem percepções de pertencimento, cuidado e respeito ao bairro e munícipio em que participam socialmente, construindo suas respectivas identidades (NEVES, 1997). 
A História Regional se apresenta, portanto, como aquela que articula a aprendizagem histórica ao cotidiano dos educandos, o que propicia que a memória, tanto coletiva como individual, perpasse vínculos e visões de diferentes gerações naquela localidade. Trabalhar tal temática permite correlacionar todos esses aspectos, promover maior reflexão crítica e criar noções valorativas entre os discentes e o ambiente em que vivem, dentre eles a escola (BARROS, 2013; FREITAS NETO, 2016). Um exemplo é a pesquisa de Serlei Ranzi (2000), desenvolvida com alunos da escola estadual Professor Júlio Mesquita. Por meio de fontes orais, entrevistas com moradores e professores do bairro, os alunos puderam estudar a história de um bairro de Curitiba/PR e de seus habitantes. Ranzi (2000) concluiu que, no início, muitos ficavam receosos devido à noção que tinham de não pertencimento histórico - noção ainda muito atrelada ao saber histórico devido às abordagens e perspectivas pouco usadas na disciplina.

O trabalho evidencia que o conhecimento histórico, com frequência, é aquele do passado, distante, quando não pouco significativo à realidade dos alunos, o que o torna menos atrativo. A proposta de estudar e pesquisar a história da localidade do aluno tem o desafio de torná-la um agente na construção do conhecimento e estimular a conexão deste saber com esferas mais amplas, nacionais e internacionais, que passem a fazer mais sentido para o discente (FONSECA, 2006, p. 4).

Tal movimento coloca os alunos e sua comunidade como membros coautores do que se conta e estuda sobre seus espaços. Desse modo, desenvolver o aprendizado sobre o local e suas particularidades no meio escolar evidencia sua ligação com o externo e como sua construção é simbólica e ativamente influenciada pelos agentes desse local - alunos, professores e comunidade -, tornando-os mais próximos e ativos no processo de construção histórica que os cerca.

Diante disso, se concebe como a variedade da História, seus personagens e meios relacionais também se diversificam ao passo que as fontes e modos de estudo e averiguações sobre o passado se ampliam. Entretanto, apesar das múltiplas possibilidades de estudo e novas descobertas e ressignificações, o ensino ainda é uma área correlata da História com diversas questões deficitárias na equação que envolve o estudo do passado e essa área. Sobretudo, quando o 
trabalho com fontes históricas, seja por sua análise ou apresentação, ainda é pouco pensado no ambiente educacional face às demais temáticas, mesmo esse sendo um tema transversal ao ensino da História.

Nesse sentido, inserir o uso didático-pedagógico de fontes é um meio de ampliar a aproximação entre ensino de História e alunos, principalmente quando essas fontes se mostram tão diversas,

[...] sair da rotina de uma aula tradicional requer mais conhecimento e dedicação. Esse desafio com certeza é grande, os livros didáticos disponíveis não estão voltados para o ensino de História Local, aí entra a pesquisa em documentos, museus, literatura e letras de música, de escritores e compositores locais, o artesanato, a arte e publicações de jornais ou revistas. O aluno precisa de estímulos e cabe ao professor desenvolver esse interesse em aprender história. Não basta falarmos em datas e personagens e sim explicitar o contexto do fato, como era a sociedade nesta época, como pensavam e o como isso interfere ou não na realidade vivenciada atualmente por eles. Mostrar que fazem parte dessa história e que podem e devem se posicionar ativamente nas transformações da sociedade. (ASSIS; BELLÉ; BOSCO, 2013, p. 3).

Como mencionado acima, o trabalho com os documentos se mostra um desafio também ao professor/historiador, como o de definir métodos e técnicas para o uso didático-pedagógico adequado, norteado e coerente à faixa etária dos alunos que se atende. Assim, de modo que o trabalho com fontes não seja de superficial ou inadequado na Educação e suas apropriações, é necessário, antes de tudo, ressignificá-lo e aproximá-lo d aluno, para que esse reconheça e aproprie-se do mesmo.

Sobrepujar as dificuldades na utilização de documentos foi um quesito fundamental no desenvolvimento do subprojeto de História aqui considerado, a fim de inserir a história local e o ambiente que circunda os alunos à sua realidade e vivência escolar.

As fontes foram compiladas entre periódicos do Núcleo de Pesquisa em História (NUPHIS), da USC, livros publicados sobre a cidade ${ }^{8}$ o acervo

\footnotetext{
${ }^{8} \mathrm{~A}$ cidade de Baru possuiu e possui muitos trabalhos realizados pelas universidades da cidade que pensam a cidade e Bauru em seus diversos meandros. Alguns deles foram editorados ao longo das últimas décadas, promovendo a publicização do saber e da história do município. Nesse sentido, foram ricas fontes ao trabalho com as temáticas de História Local e Regional. Assim, também atuaram como fonte: Neves (1971).
} 
imagético/visual digitalizado do Museu Histórico Ferroviário Regional de Bauru, o repositório on-line do JcNet, imagens fotográficas levadas pelos alunos e os relatos coletados por eles a partir de informações familiares.

O trabalho assistido por estas fontes documentais foi de grande valia ao PIBID História, que ao abordar a prática da História Local e Regional, buscou aproximar o conhecimento histórico à História dos alunos e de seu cotidiano. É certo que o tratamento da temática História Local e Regional encontrou limitações para o seu desenvolvimento, sobretudo devido às poucas informações acessíveis e ao pouco conhecimento dos alunos sobre o bairro e o município em que vivem. Sem uma história prévia escrita sobre o Núcleo Habitacional Gasparini e como meio de superar a dificuldade, o trabalho de identificação e seleção de fontes requereu muitos cuidados de averiguação, a fim de que se norteasse de modo a ser o mais esclarecedor possível aos alunos quanto às possibilidades de informações, de seus discursos e o modo de se chegar a um saber coerente. Diante dessa busca, objetivou-se a organização de um conteúdo que fosse construído pelos próprios alunos, que unisse o uso de fontes por esses e que atuasse no sentido de ser um meio divulgador da produção realizada durante o Projeto. Este intento manifestou-se na construção de uma página online da Wikipédia. 
Imagem 1 - Página da Enciclopédia On-line escrita pelos alunos da E. E. Edison Bastos Gasparini.

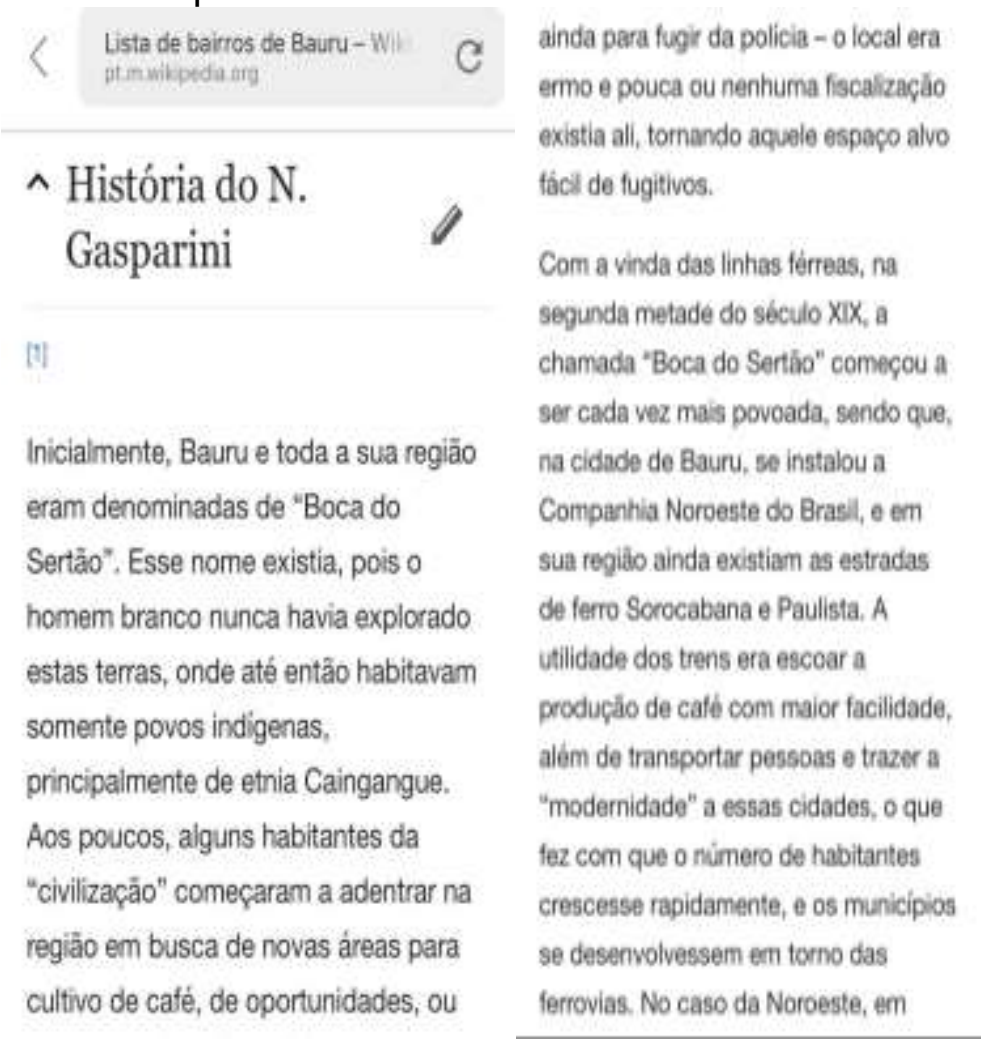

Fonte: (LISTA..., 2020).

Por meio das leituras e discussões semanais, os graduandos participantes e professores orientadores refletiram sobre aspectos teóricos e metodológicos de uma pesquisa em História Local; as técnicas e os cuidados para desenvolvê-la; o trabalho com os documentos e suas conotações ideológicas; bem como com a sua aplicação em atividades escolares com a finalidade de que os alunos pudessem vislumbrar diferentes visões e seus embates na construção da memória da qual estavam, ou não, inseridos, e maneiras de conectar a experiência histórica local com a nacional e internacional.

Para isso, utilizou-se de atividades lúdicas e informativas que procuraram mostrar aos estudantes participantes novos modos de ver e se apoderarem de sua cidade, seu bairro e da história que permeia a formação dos mesmos. A proposta foi de criar, de imediato e em longo prazo, uma consciência coletiva sobre a importância dos recursos e das memórias locais, pois acredita-se que com o sentimento de pertencimento e de cidadania é que se construíra uma relação sustentável e preservacionista entre o indivíduo e a cidade. 
Ao perscrutar as possibilidades de fontes a respeito do local em estudo, alguns meios foram selecionados como o uso de documentário, jornais on-lines e diários, cartas, fotografias e jornais do acervo do NUPHIS, da Universidade do Sagrado Coração, que conta com amplo repositório de documentos locais de Bauru, que permitem, acima de tudo, recontar a história do bairro através de seu fundador e demais documentos que abarcam a cidade de Bauru ao longo das páginas dos jornais.

Todas as informações foram compiladas por licenciandos pibidianos e alunos em questionários realizados em sala, e pelos alunos, em suas casas; em informações obtidas na sala de informática da escola, que eram analisadas no sentido de considerar a veracidade da informação, seus autores, os veículos de divulgação sobre o bairro e fontes históricas que pudessem ser usadas na pesquisa, buscadas nos acervos digitais de jornais e no próprio NUPHIS, nesse por parte dos professores bolsistas, principalmente. Ainda, as atividades sempre foram norteadas no sentido de promover simultaneamente ao estudo do Local e de fontes, o uso de TDIC's na realidade dos alunos, pois esses, como nativos digitais, demonstravam facilidade e maior interesse nas atividades permeadas pelo uso tecnológico. O que, apesar dos frequentes e variados desafios de sua inserção no processo de ensino aprendizagem (MORÁN, 2015), estimulou, dentro das possibilidades estruturais da escola parceira do Projeto, o uso frequente de metodologias alternativas, que envolviam vídeos, pesquisas, uso de jornais e demais recursos on-line que possibilitaram promover a união de diversos recursos para a construção de um ciclo do ensino de História Local.

Mesmo a restrição de equipamentos na sala de informática, com número limitado de computadores, se mostrou um meio articulador de novas possibilidades com a organização de subtemáticas trabalhadas em pequenos grupos, que se tornou um método de atrativo, efetivo e, sobretudo, produtivo aos alunos atendidos. Seu uso, principalmente nas pesquisas relacionadas às notícias do bairro Gasparini no acervo on-line do JCnet $^{9}$, trouxe informações sobre o vínculo entre o nome do bairro e o da escola com o prefeito da cidade

\footnotetext{
${ }^{9} \mathrm{O}$ JcNet é a versão digital do jornal impresso bauruense chamado Jornal da Cidade (2018), que circula na cidade e região. As edições diárias contam com notícias cotidianas e espaços especiais dedicados aos editoriais. A coluna Tribuna do Leitor, dedicada a esses editoriais, costuma receber importantes trabalhos e contribuições de docentes e discentes das universidades sediadas na cidade, como fomento à disseminação e publicização do saber produzido na instância acadêmica.
} 
Edison Gasparini, cujo posicionamento político de esquerda resultara na cassação de seu mandato a vereança no momento do golpe de Estado pelos militares, em março de 1964. Eleito prefeito no início dos anos de 1980, estimulou a criação de vários bairros e enalteceu a história dos populares, perceptível nos nomes das ruas do bairro Gasparini, todas elas dedicadas a atividades laborais como ferroviários, pintores, gráficos, professores, contabilistas, atletas, comerciários, secretárias, açougueiros, costureiras, pedreiros, carpinteiros e lavradores, cabeleireiros e mecânicos.

Outra atividade possível foi 0 uso do recurso digital My maps ${ }^{10}$, especialmente para uma das aulas/oficinas, que reconstruiu o espaço do bairro e suas principais ruas, momento em que os alunos redimensionaram o seu ambiente geográfico ao universo da cidade de Bauru, compreendo a sua distribuição e composição social a partir das pesquisas realizadas.

Destaca-se que mesmo com dificuldades no uso dos computadores, o trabalho e pesquisa em grupos em relação à História Local e do bairro tornaram a atividade diária mais instigante, produtiva e também proporcionaram a valorização e criticidade dos discentes em relação ao próprio bairro, à sua organização, cuidados, ou falta deles, a conexão de sua história com a vivenciada por eles e familiares, ou seja, a compreensão do local em um período de sobreposição deste por amplas informações sobre o global. (MARTINS, 2009).

A partir das pesquisas, relatos orais discutidos e buscados pelos alunos, o trabalho em grupo se fez novamente presente e evidenciou a participação desses enquanto moradores, e, enquanto construtores de saberes sobre a história de onde vivem e, em particular, como produtores de uma página da Wikipédia ${ }^{11}$ que os têm como autores. Diante disso, a articulação da construção da História do Bairro Gasparini e de Bauru divulgadas nesta página permitiu que os alunos aprimorassem tais atividades, tivessem acesso a novos ambientes e melhorassem significativamente o seu desempenho em relação ao domínio tecnológico, às formas de acesso às informações e aos documentos, à análise

\footnotetext{
${ }^{10} \mathrm{O}$ My maps, do Google, consiste em um recurso digital que cria e personaliza mapas, com base nos dados do próprio software. A atividade pensada com base nele consistia no mapeamento das ruas do bairro, próximas ao perímetro da escola. De modo específico, a partir do recorte do mapa do bairro em questão, os estudantes assinalavam o percurso feito por eles até a escola e reconheciam os nomes das ruas, verificando a historicidade de cada um deles

11 (LISTA..., 2020).
}

História \& Ensino, Londrina, v. 26, n.1, p. 160-180, jan./jun. 2020 
crítica deste material, ao uso da escrita e da ortografia. Ademais, a intervenção pedagógica garantiu que os mesmos tivessem papel ativo na construção do saber dentro de uma perspectiva criativa e crítica, já que pesquisaram e analisaram em sites e jornais on-line informações e notícias sobre o espaço em que vivem e atuam, sendo substancialmente ativos em todo o processo de construção e articulação de saberes históricos e localidade em escalas reverberadas. Esta experiência respondeu à nossa indagação inicial de como as ferramentas digitais podem ser úteis e instigantes no ensino e na produção do conhecimento histórico.

Isto posto, a História Local, muito mais do que um local geográfico, apresentado, ainda com frequência, segundo 0 mito de origem dos "conquistadores e grande homens", como aponta Fonseca (2006), é uma temática que instiga a problematização, que busca conhecer o heterogêneo, as diferenças culturais, os problemas, as exclusões e o ocultamento nas narrativas "vencedoras". O estudo e uso da História da Localidade deve cogitar a terra e suas relações com o homem, os diferentes tipos de poderes e conflitos (ou no caso, micro poderes, apontados por RANZI, 2000), as unidades espaciais em que exercem esses poderes e símbolos, a cultura, a periodização e a diacronia (MATTOSO, 1988) ao ser construída.

\section{Considerações Finais}

O estímulo dos graduando pibidianos à pesquisa, ao estudo, à análise de fontes orais e imagéticas e ao manuseio de ferramentas digitais pelos alunos do $6^{\circ}$ ano resultou na construção de conhecimentos singulares da história do bairro em que estes habitam - Gasparini, e de suas conexões com a cidade de Bauru e do país. O uso de Tecnologias da Informação e Comunicação (TDIC's) mostrouse favorável no processo de ensino, na busca de dados e na organização do saber, bem como em sua disponibilização para o público em geral, motivo de alegria e orgulho dos alunos e pibidianos.

Algumas dificuldades foram sentidas em relação à obtenção de informações, tanto por parte dos educandos como dos educadores, uma vez que os livros didáticos, no geral, pouco tratam da temática da História Local, e os arquivos, 
principalmente sobre o bairro estudado, são escassos. Dessa maneira, para chegarmos aos objetivos propostos, foram analisados materiais do NUPHIS, da Universidade do Sagrado Coração, documentário, pesquisas on-line em acervos de jornais, bem como os resultados das pesquisas orais e fotográficas realizadas pelos alunos junto a seus familiares. Estes materiais e as memórias coletadas foram fundamentais para que pudessem construir uma narrativa a respeito da história local proposta pelo projeto PIBID de História.

A relevância do projeto residiu no fato de que os alunos participantes se perceberam atuantes na construção da historicidade de sua comunidade e não apenas receptores de uma história formulada sobre a cidade, então pouco conectada à história do bairro. O PIBID/História propiciou que os estudantes do EF percebessem o ambiente em que residem, estudassem sobre ele e compreendessem suas dinâmicas, desenvolvendo um olhar crítico acerca daquela região. Experiência que propiciou múltiplas percepções sobre um mesmo local que não compreende somente a cidade, mas a história do bairro, de suas ruas, seus comércios, da comunidade escolar e das trajetórias familiares, que levaram em conta os sentimentos, as culturas, as vivências e suas memórias para se moldar.

Ao final do projeto, com o uso das informações obtidas por professores e alunos, foi idealizada uma página no site Wikipédia que trata da história do bairro Gasparini. A importância desse material é visualizada, uma vez que, como já explicitado, poucas são as fontes que trazem informações sobre a temática da História Local, além de estimular que os próprios alunos buscassem, organizassem e divulgassem esse conhecimento, em um importante exercício de pesquisa, identificação e seleção de fontes e participantes reais da construção da História de seu local de vivência. Outro fator positivo foi a experiência realizada pelos graduandos pibidianos como mediadores na construção de um saber crítico e coletivo, propiciado pelo uso de fontes e facilitado pelas ferramentas das Tecnologias da Informação e Comunicação.

\section{Agradecimentos}

Nossos agradecimentos ao apoio do Programa Institucional de Iniciação à Docência (PIBID/CAPES) e da Universidade do Sagrado Coração - USC; aos 
coordenadores da Escola Estadual Prefeito Edison Bastos Gasparini, em particular ao prof. de História Daniel Pereira Silva, que acompanhou os bolsistas nas atividades realizadas com as turmas de sexto ano. As ideias aqui apresentadas são de responsabilidade dos autores deste texto.

\section{Referências}

ALVES, Elaine Jesus. Literacia digital de professores: competências e habilidades para o uso das TDICs na docência. In: ENDIPE - ENCONTRO NACIONAL DE DIDÁTICA E PRÁTICA DE ENSINO, 17., 2014, Fortaleza. Anais [...]. Fortaleza: Editora UECE, 2014. Disponível em: http://www.uece.br/endipe2014/ebooks/livro1/314$\% 20$ LITERACIA\%20DIGITAL\%20DE\%20PROFESSORES\%20COMPET\%C3\%8ANCI AS\%20E\%20HABILIDADES\%20PARA \%200\%20USO $\% 20$ DAS $\% 20$ TDIC $\% 20$ NA $\%$ 20DOC\%C3\%8ANCIA.pdf. Acesso em: 7 set. 2018.

ASSIS, Elisabete Xavier de; BELLÉ, Kássia; BOSCO, Vania Dilma. O ensino da história local e sua importância. REDIVI, Itajaí, v. 1, n. 1, p. 1-9, 2013. Disponível em: https://siaiap32.univali.br/seer/index.php/redivi/article/view/5089/4266. Acesso em: 7 ago. 2018.

BARROS, Carlos Henrique Farias de. Ensino de história, memória e história Local. Criar Educação, Criciúma, v. 2, n. 2, 2013. Disponível em:

http://periodicos.unesc.net/criaredu/article/view/1247. Acesso em: 24 set. 2018.

BARROS, José D'Assunção. História, espaço e tempo: interações necessárias. Varia História, Belo Horizonte, v. 22, n. 36, p. 460-475, jul./dez. 2006.

Disponível em: https://www.scielo.br/pdf/vh/v22n36/v22n36a12.pdf. Acesso em: 29 abr. 2020.

BIZELLI, José Luis; GERALDI, Luciana Maura Aquaroni. O uso das tecnologias da informação e comunicação no ensino médio público. In: LEÃO, Andreza Marques de Castro; MUZZETI, Luci Regina (org.) Perspectivas, práticas e reflexões educacionais. São Paulo: Cultura Acadêmica, 2016. p. 147-164.

BLOCH, Marc. A História, os homens e o tempo. In: BLOCH, Marc. Apologia da história: ou o ofício do historiador. Rio de Janeiro: Zahar, 2001. p. 51-68.

BRASIL. Ministério da Educação . Apresentação do Programa Institucional de Bolsas de Iniciação à Docência. Brasília: MEC, 2018. Disponível em: http://portal.mec.gov.br/pibid. Acesso em: 30 abr. 2019.

BRASIL. Ministério da Educação. Parâmetros Curriculares Nacionais: introdução. Brasília: MEC, 1998a. 
BRASIL. Ministério da Educação. Parâmetros Curriculares Nacionais: temas transversais, pluralidade. Brasília: MEC, 1998b.

BRASIL. Ministério da Educação. Parâmetros Curriculares Nacionais (Pluralidade cultural). Brasília: MEC, 1997a.

BRASIL. Ministério da Educação. Parâmetros Curriculares Nacionais: história, geografia. Brasília: MEC, 1997b.

CAPRINI, Aldieris Braz Amorim. Pesquisa em história regional: aspectos conceituais e metodológicos. III Simpósio ILB, [S. I.], v. 12, p. 13, 2010. Disponível em: https://docplayer.com.br/22237582-Pesquisa-em-historiaregional-aspectos-conceituais-e-metodologicos.html. Acesso em: 2 maio 2020.

COSTA, Sandra Regina Santana; DUQUEVIZ, Bárbara Cristina; PEDROZA, Regina Lúcia Sucupira. Tecnologias digitais como instrumentos mediadores da aprendizagem dos nativos digitais. Revista Quadrimestral da Associação Brasileira de Psicologia Escolar e Educacional, São Paulo, v. 19, n. 3, p. 603-610, set./dez. 2015. Disponível em: http://www.scielo.br/pdf/pee/v19n3/2175-3539pee-19-03-00603.pdf. Acesso em: 9 jan. 2018.

FEITOSA, Lourdes Madalena Gazarini Conde. Amor e sexualidade: o masculino e o feminino em grafites de Pompéia. São Paulo: Fapesp: Annablume, 2005.

FONSECA, Selva Guimarães. História local e fontes orais: uma reflexão sobre saberes e práticas do ensino de história. Revista História Oral, [Recife], v. 9, n. 1, p. 125-141, jan./jun. 2006. Disponível em:

http://revista. historiaoral.org.br/index.php?journal=rho\&page=article\&op =view\& path\%5B\%5D=193. Acesso em: 23 set. 2018.

FREIRE, Paulo. Pedagogia do oprimido. 17. ed. Rio de Janeiro: Paz e Terra, 1987.

FREITAS NETO, José Alves. A transversalidade e a renovação no ensino de história. In: KARNAL, Leandro. (org.). História na sala de aula: conceitos, práticas e propostas. 6. ed. São Paulo: Contexto 2016. p. 57-74.

GASPARELLO, Arlette Medeiros. Encontros de saberes: as disciplinas escolares, o historiador da educação e o professor. In: MONTEIRO, Ana Maria; GASPARELLO, Arlette Medeiros; MAGALHÃES, Marcelo de Souza (org.). Ensino de história: sujeitos, saberes e práticas. Rio de Janeiro: Mauad: Faperj, 2007. p. 73-89.

JORNAL DA CIDADE. Bauru, 11 set. 2018.

LISTA de Bairros de Bauru. In: WIKIPEDIA: a enciclopédia livre. 2020. Disponível em: https://pt.wikipedia.org/wiki/Lista_de_bairros_de_Bauru. Acesso em: 28 abr. 2020.

MARTINS, Ismênia de Lima. História e ensino de história: memória e identidades sociais. In: MONTEIRO, Ana Maria; GASPARELLO, Arlette Medeiros; MAGALHÃES, Marcelo de Souza (org.). Ensino de história: sujeitos, saberes e práticas. Rio de Janeiro: Mauad: Faperj, 2007. p. 13-21. 
MARTINS, Marcos Lobato. História regional. In: PINSKY, Carla Bassenezi (org.). Novos temas nas aulas de História. São Paulo: Contexto, 2009. p. 135-152.

MATTOSO, José. A história regional e local. In: MATTOSO, José. A escrita da história: teoria e métodos. Lisboa: Imprensa Universitária, 1988. p. 168-194.

MORÁN, José. Mudando a educação com metodologias ativas. In: SOUZA, Carlos Alberto de; MORALES, Ofélia Elisa Torres (org.). Convergências midiáticas, educação e cidadania: aproximações jovens. Ponta Grossa: UEPG, 2015. (Coleção Mídias Contemporâneas). p. 15-33.

NEVES, Correia das. Tipos populares de Bauru. Bauru: Tilibra, 1971.

NEVES, Joana. História local e construção de identidade social. Revista Saeculum, João Pessoa, n. 3, p. 13-27, jan./dez. 1997. Disponível em: http://periodicos.ufpb.br/index.php/srh/article/view/11226/6341. Acesso em: 17 mar. 2018.

NOGUEIRA, Natania Aparecida da Silva; SILVA, Lucilene Nunes. Os desafios para a construção de uma história local - o caso de Leopoldina, Zona da Mata de Minas Gerais. Polyphonía, Goiânia, v. 21, n. 1, jan.-jun. 2010, p. 229-242. Disponível em: https://doi.org/10.5216/rp.v21i1.16310. Acesso em: 16 set. 2020.

PAIM, Elison Antonio; PICOLLI, Vanessa. Ensinar história regional e local no ensino médio: experiências e desafios. História \& Ensino, Londrina, v. 13, p. 107126, set. 2007. Disponível em:

http://www.uel.br/revistas/uel/index.php/histensino/article/view/11647/10331. Acesso em: 6 out. 2018.

PINSKY, Jaime; PINSKY, Carla Bassanezi. Por uma história prazerosa e consequente. In: KARNAL, Leandro (org.). História na sala de aula: conceitos, práticas e propostas. 5. ed. São Paulo: Contexto, 2007. p. 17-36.

RAGO, Margareth; GIMENES, Renato Aloizio Oliveira (org.). Narrar o passado, repensar a história. 2. ed. Campinas: UNICAMP: IFCH, 2014.

RANZI, Serlei Maria Fischer. Fontes orais, história e saber escolar. In: CONGRESSO BRASILEIRO DE HISTÓRIA DA EDUCAÇÃO, 1., 2000, Rio de Janeiro. Anais [...]. Rio de Janeiro: [Scielo], 2000. p. 29-42. Disponível em: http://www.scielo.br/pdf/er/n18/n18a04.pdf. Acesso em: 5 jan. 2019.

SAMUEL, Raphael. Documentação - história local e história oral. Revista Brasileira de História, São Paulo, v. 9, n. 19, p. 219-243, set./fev. 1989 -1990. Disponível em: file:///C:/Users/HP\%20PAVILION/Downloads/raphaelsamuel.pdf. Acesso em: 25 nov. 2018.

SCHMIDT, Maria Auxiliadora; CAINELLI, Marlene. História local e o ensino de história. In: SCHMIDT, Maria Auxiliadora Moreira dos Santos (org.). Ensinar história: pensamento e ação no magistério. São Paulo: Scipione, 2004. p. 111124. 
SILVA, Edson Armando; PEREIRA, Marco Aurélio Monteiro. Balanço aos 20: a Revista de História Regional no campo historiográfico brasileiro. Revista de História Regional, Ponta grossa, v. 21, n. 2, p. 307-337, 2016. Disponível em: https://www.revistas2.uepg.br/index.php/rhr/article/view/9490. Acesso em: 2 maio 2020.

SOBRE os Trilhos da História. Direção: Evandro Souza. Brasil: Libratian Files, 2016. 1 vídeo (26 min). Disponível em:

https://www.youtube.com/watch?v=tL7f1BwZcF0. Acesso em: 25 abr. 2020.

TOLEDO, Maria Aparecida Leopoldino Tursi. História escolar e escrita da história: por uma historiografia do ensino de história. In: MOLINA, Ana Heloísa. et al. (org.) Ensino de história e educação: olhares em convergência. Ponta Grossa: Editora da UEPG, 2012. p. 225-248. 